NIST Technical Note 1824

\title{
Guidance on Fire Emergency Procedures for Emergency Stair Travel Devices
}

\author{
Erica D. Kuligowski
}

http://dx.doi.org/10.6028/NIST.TN.1824

National Institute of Standards and Technology U.S. Department of Commerce 


\section{Guidance on Fire Emergency Procedures for Emergency Stair Travel Devices}

Erica D. Kuligowski

Fire Research Division

Engineering Laboratory

http://dx.doi.org/10.6028/NIST.TN.1824

November 2013

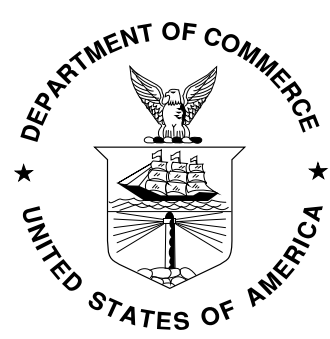

U.S. Department of Commerce Penny Pritzker, Secretary

National Institute of Standards and Technology Patrick D. Gallagher, Under Secretary of Commerce for Standards and Technology and Director 
Certain commercial entities, equipment, or materials may be identified in this document in order to describe an experimental procedure or concept adequately. Such identification is not intended to imply recommendation or endorsement by the National Institute of Standards and Technology, nor is it intended to imply that the entities, materials, or equipment are necessarily the best available for the purpose.

National Institute of Standards and Technology Technical Note 1824 Natl. Inst. Stand. Technol. Tech. Note 1824, 22 pages (November 2013) CODEN: NTNOEF http://dx.doi.org/10.6028/NIST.TN.1824 

Abstract
This document provides specific detailed guidance and recommendations on the use of emergency stair travel devices for evacuation of persons with mobility impairments during fire emergencies in buildings. The people who would find this document useful are those who develop fire evacuation plans for building occupants (i.e., building owners, building managers, fire protection engineers, fire marshals, etc.), since they may be considering the use of emergency stair travel devices for evacuation of people with mobility impairments in their buildings.
There are seven main topics covered by this guidance document, and these are listed here:
1) Identifying the types of emergency stair travel devices available on the market
2) Deciding whether emergency stair travel devices offer appropriate evacuation solutions for your building
3) Selecting the number and type of emergency stair travel devices
4) Locating emergency stair travel devices throughout the building
5) Operating emergency stair travel devices during a fire emergency
6) Training on the use of emergency stair travel devices
7) Maintaining emergency stair travel devices

Keywords: Disabled, egress, evacuation, fire safety, human behavior, mobility impairments 



\section{Table of Contents}

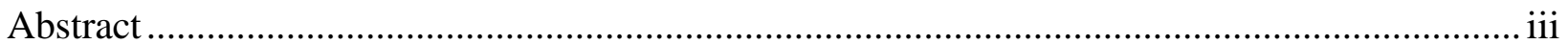

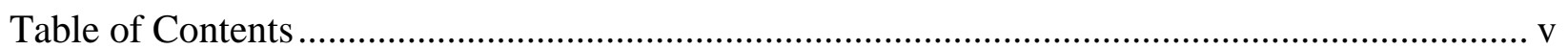

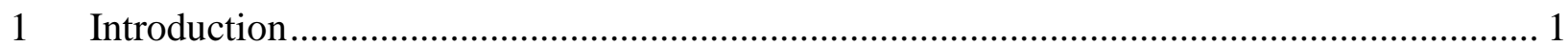

2 Types of emergency stair travel devices available on the market ..................................... 2

3 Deciding whether emergency stair travel devices offer appropriate evacuation solutions for

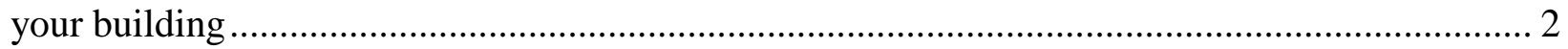

3.1 Who are the stakeholders and what do they think? ................................................. 3

3.2 Can your building and stair configuration accommodate the appropriate use of emergency stair travel devices for evacuation? ............................................................... 3

4 Selecting the emergency stair travel device number and type .......................................... 3

4.1 The number of people who require emergency stair travel devices:............................. 4

4.2 The type of emergency stair travel device required ................................................. 6

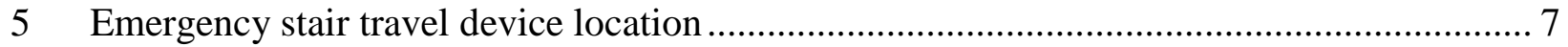

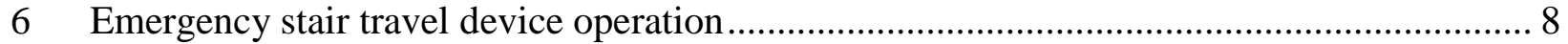

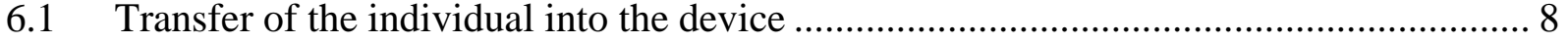

6.2 Location of the transfer of the individual into the device ......................................... 9

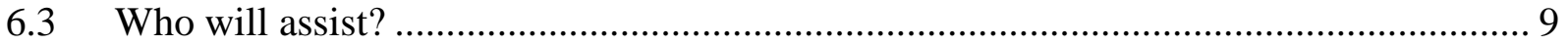

6.4 The number of operators (for track/belt type devices) ............................................ 11

6.5 Travel on horizontal building components........................................................... 11

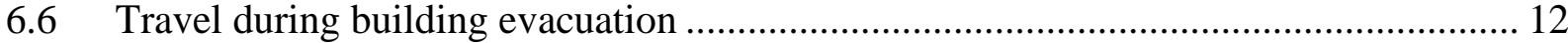

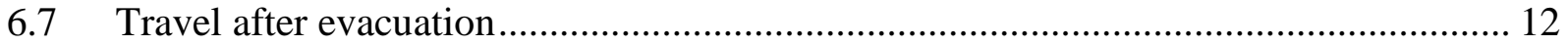

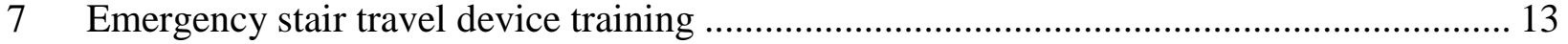

8 Emergency stair travel device maintenance................................................................... 14

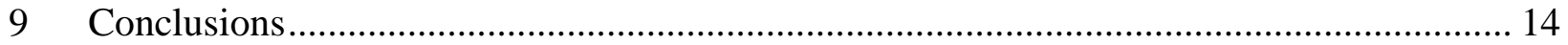

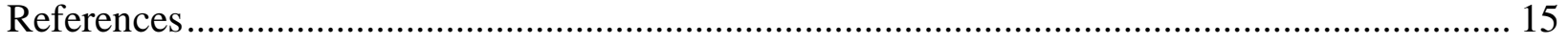




\section{Introduction}

In all General Services Administration (GSA) buildings, exit stairways are provided as the main method of evacuation during fires. However, stairways do not offer equal opportunity to reach safety for all building occupants. For example, people with mobility impairments (e.g., persons with arthritis, persons needing assistance, persons using wheelchairs, etc.) may experience severe difficulty in negotiating the stairways during an evacuation, including not being able to traverse the stairways at all (with the only option available to wait in place in a safe area on the floor). Therefore, and especially since the tragic loss of life in the 2001 World Trade Center attacks, engineering efforts have refocused on efficient evacuation procedures, especially for occupants who cannot negotiate the stairs without assistance.

The General Services Administration's general approach in the construction of new facilities and projects in existing buildings is to incorporate cost-effective fire protection and life safety systems and procedures that result in overall building safety that meets or exceeds the levels required by local building codes. Based on previous GSA/NIST research and the efforts of the ASME A17.1/CSA B44 Task Groups on Elevators and Fire, new provisions have recently appeared in the International Building Code (2012) and the National Fire Protection Association (2012), which permit the use of passenger elevators in buildings for occupant evacuation. The use of these elevators by building occupants can improve the overall evacuation time compared with the use of exit stairs only, in addition to improving the evacuation capability for persons with mobility impairments.

Another system that can be used to improve the evacuation capability for persons with mobility impairments is emergency stair travel devices. Emergency stair travel devices, based on the definition provided by the Rehabilitation Engineering and Assistive Technology Society of North American (RESNA) standard, are the following: devices "whose primary purpose is the travel of partial or fully immobile individuals over stair and horizontal surfaces during building evacuations” (RESNA 2013). Similarly, a standard was recently developed that provides requirements on the design and testing of emergency stair travel devices. However, in both cases, very little research or efforts have been performed that result in the development of guidance and recommendations for standardized and data-driven procedures to safely evacuate persons with mobility impairments from tall buildings using these systems.

Therefore, the purpose of this document is to provide specific detailed guidance and recommendations on the use of emergency stair travel devices for evacuation of persons with mobility impairments during fire emergencies in buildings. The people who would find this document useful are those who develop fire evacuation plans for building occupants (i.e., building owners, building managers, fire protection engineers, fire marshals, etc.), since they may be considering the use of emergency stair travel devices for evacuation of people with mobility impairments in their buildings.

There are seven main topics covered by this guidance document. First, this document will briefly outline the three main types of emergency stair travel devices available on the market. Then, the document will focus primarily on one type (i.e., the type upon which the RESNA standard also 
focuses). Second, the document will present the factors to consider when deciding whether emergency stair travel devices are appropriate evacuation solutions for a building. Third, the document outlines the factors to consider when selecting the number and type of emergency stair travel device for a building. Fourth, the document identifies the factors to consider when locating the emergency stair travel devices inside the building. Fifth, the document discusses the operation of the devices (on and off the stairways). Sixth, the document identifies guidance on training. Finally, the document ends with a brief discussion on emergency stair travel device maintenance.

\section{Types of emergency stair travel devices available on the market}

There are a range of devices that can be used for emergency evacuation, including wheelchairs that descend and ascend stairs, platforms and chairs installed on the staircase, wheelchair carriers that transport the individual while occupying a wheelchair, and evacuation chairs (or stair travel/descent devices) used during emergencies (Hedman 2009; 2010). A recent survey of commercially-available devices found a total of 34 emergency stair travel devices produced by 12 manufacturers around the world. The 34 devices fall into one of the three design categories:

a) Devices which use a track or belt system which contacts the stair nosings (14 devices). The weight of these type of devices ranges from $10 \mathrm{~kg}$ to $20.7 \mathrm{~kg}(22 \mathrm{lb}$ to $46 \mathrm{lb})$. The maximum user weight of the device ranges from $130 \mathrm{~kg}$ to $228 \mathrm{~kg}$ ( $287 \mathrm{lb}$ to $500 \mathrm{lb}$ ), with most devices rated for $150 \mathrm{~kg}(330 \mathrm{lb})$. The range of overall width of these devices is from $42.6 \mathrm{~cm}$ to $58.4 \mathrm{~cm}$ (16.8 in to 23 in).

b) Devices which are supported or carried by one or more persons, and either roll along the stair riser and tread, or are carried (19 devices).

c) Devices which comes in contact with the stairs, but use other designs (e.g., sled type) (one device)

This guidance document focuses only on the devices which use a track or belt system, since the focus of the RESNA standard (2013) entitled "RESNA ED-1 Evacuation Devices Volume 1: Emergency Stair Travel Devices for Individuals with Disabilities" is on the performance of Track-Type, controlled-descent, manual-ascent emergency stair travel devices.

\section{Deciding whether emergency stair travel devices offer appropriate evacuation solutions for your building}

This section focuses on the factors to consider when deciding whether emergency stair travel devices are appropriate for your building. An understanding of the stakeholders and their perspective on emergency stair travel devices, the building's current evacuation strategy for persons unable to negotiate the stairs, and the building's stair configuration (and any limitations this configuration might provide for the use of these devices) are important in this decision. 


\subsection{Who are the stakeholders and what do they think?}

First, it is important to understand who are the stakeholders involved in this decision and what are their perspectives on the device. Stakeholders can include, but are not limited to, the building manager or owner, designated officials responsible for developing the building fire safety and evacuation plans, fire protection engineer or fire marshal, local fire department personnel, building occupants or visitors who will use the emergency stair travel device, and skilled/trained personnel who will be guiding the device down the stairs (which, in some cases, may be fire department personnel). In some buildings, for example, a local fire department or fire marshal may not endorse the use of emergency stair travel devices for evacuation of building occupants. Additionally, the mobility impaired occupants in your building may not feel comfortable using these types of devices for evacuation. In either one of these cases, the use of emergency stair travel devices may not even be an option for consideration. Therefore, all stakeholders need to be involved in the decision-making process, especially those who will be in charge of operation and those who will be using the devices.

\subsection{Can your building and stair configuration accommodate the appropriate use of emergency stair travel devices for evacuation?}

The next question asks whether your building can accommodate the use of an emergency stair travel device. As mentioned in Section 1, the overall widths of emergency stair travel devices currently on the market range from $42.6 \mathrm{~cm}$ to $58.4 \mathrm{~cm}$ (16.8 in to 23 in). The designated official in charge of developing the building's fire safety and evacuation plan should obtain information on the width and turning radius of these types of devices and ensure that the stair(s) and exit corridors (if applicable) in which these would be used allow for effective and safe movement of the device. Identify which devices, if any, meet the width and turning radius requirements of your building's exit pathways configuration. If none of the devices on the market meet your building's width and turning radius requirements, then it is unlikely that the use of emergency stair travel devices will offer an appropriate evacuation solution for your building and its occupants. If some (or all) devices on the market meet your building's width and turning radius requirement, make a list of these devices (to be used later in this guidance document).

\section{Selecting the emergency stair travel device number and type}

If stakeholders are in agreement that emergency stair travel devices offer a possible evacuation solution and your building can accommodate the use of such devices, then the next set of decisions involves selection of emergency stair travel devices for your building. The steps in this section outline how to select the number and type of emergency stair travel devices for a building. 


\subsection{The number of people who require emergency stair travel devices:}

Step 1: What is meant by disabled? The first step is to define what is meant by "disabled" in your building. In reference to the use of emergency stair travel devices, disabled could mean those who are mobility-impaired, or individuals who are unable to negotiate the stairs without assistance from people or devices. This group can also consist of individuals who do not feel comfortable navigating the stairs without assistance (e.g., persons with arthritis, persons with temporary mobility injuries, such as a broken leg, etc.).

Note: 'What is a disability' is covered in the following document: (United States Fire Administration document 1999)

Step 2: Who is disabled in your building, and are they in need of assistance? It is possible that in your building, people with mobility disabilities have self-identified. If so, you already have a list of these individuals. If building occupants have self-identified as disabled or in need of assistance, review the nature of their current disabilities with them, if they are willing to share. This will help you understand if they are in need of assistance during evacuation, and in turn, may wish to use an emergency stair travel device for evacuation.

If the occupants in your building do not self-identify, one option might be to speak with management (throughout the building) about their staff. Management can let you know about their employees with whom you may need to speak with about emergency stair travel devices. Another option is to send out a building-wide email asking for individuals to self-identify as 'in need of assistance during an evacuation' - i.e., the email can explain that the building is considering purchasing new emergency stair travel devices, provide a description of the device and its purpose, and ask people to please identify themselves as someone who would be willing to use an emergency stair travel device in emergencies. Let them know that self-identification is voluntary, and their information will be kept confidential and shared only with those who have responsibility in emergency response (Kailes 2002).

Another option is to send out a checklist to building occupants. As an example, a checklist is available for people unable to negotiate the stairs, entitled: "Will You Need Assistance in an Emergency Evacuation?” With this checklist, again, let them know that self-identification is voluntary, and their information will be kept confidential and shared only with those who have responsibility in emergency response (Kailes 2002).

The next step to consider is to estimate the number of disabled visitors to you building. If your building is restricted from having visitors, this is not an issue. For buildings with visitor access, there are ways to estimate numbers of expected visitors with disabilities. For example, if all visitors must register ahead of time before entering your building, your building may already (or may wish to) ask about disability needs upon registration (as long as these questions adhere to ADA or equivalent confidentiality requirements). Another option is to estimate the percentage of mobility impaired individuals that may be stationed in your building on any given day, based upon U.S. population (U.S. Census 2011; Social Security Administration, Accessed 2012) and/or U.S. disability statistics. For example, the Disability Statistics website (www.disabilitystatistics.org) provides statistics on the prevalence of non-institutionalized 
disabled individuals based upon the following factors: gender, age, races, ethnicity, education, and disability type in any given year (from 2008-2011). According to this website, $6.9 \%$ of the U.S. population (independent of gender, age, race, ethnicity, education) reported an ambulatory disability in 2011. The statistics can also be filtered and estimated for each state in the United States.

Step 3: Where are individuals with disabilities located (or where will they be located) in your building? The next step involves identifying the floors on which people with disabilities work or visit in your building. If these individuals (both building occupants and visitors) will only access the ground floor of the building, then they will likely not require an emergency stair travel device (unless the ground floor is not located on the same level as the outdoor designated evacuation assembly area).

Step 4: Identify the mobility-impaired individuals (occupants and visitors, if possible) who are (or will be) located on floors higher than the ground floor. In this case, the ground floor refers to the floor located on the same level as the outdoor evacuation area. This helps you understand the number of people with disabilities you will need to protect in your building.

Step 5: Of those individuals identified in Step 4, inquire about how many people are unwilling to use an emergency stair travel device in your building for use during fire emergencies. It is possible that there are individuals who are not comfortable with the idea of evacuating via an emergency stair travel device. Individuals using these types of devices are completely reliant upon other individuals for the operation of the device, which could be a difficult and fearprovoking task. Be sure to discuss this evacuation strategy with all disabled persons to first understand if they are willing to use this type of device for vertical descent.

Step 6: Of those individuals identified in Step 4, inquire about how many people are unable to use an emergency stair travel device in your building for use during fire emergencies. There could be instances where the individuals' mobility disabilities are too severe or incongruent with the use of an emergency stair travel device. For example, individuals who use a special type of motorized wheelchair and cannot be removed from the chair for any period of time, or those with suspected spinal injuries, may be unable to use an emergency stair travel device for evacuation during fire emergencies.

Step 7: Add the numbers obtained from Step 4, and subtract any individuals identified in Steps 5 and 6, to obtain the number of individuals willing and able to use emergency stair travel devices in your building (both building occupants and potential visitors).

Step 7 provides the number of emergency stair travel devices needed in your building, if each disabled occupant or visitor is to have one device assigned to them for use during evacuation. This method will ensure that each disabled individual has his/her own emergency stair travel device. This is the most conservative method to provide evacuation safety (via emergency stair travel devices) to all disabled occupants in (or expected in) your building.

However, there are possibilities for reducing the number of devices in your building. These possibilities are the following: 
1) Devices may be reduced if the fire department will also arrive with additional devices to be used during evacuation (note: it is important to find out how many devices they will bring); and if the fire department is close enough that they will arrive to the building during the timing necessary to evacuate the building. In other words, it is not acceptable to have the occupant with mobility impairments waiting a significant amount of time especially if all others have evacuated - before they can start their evacuation [unless this is part of the accepted fire safety and evacuation plan for the building].

2) If the building is fully sprinklered and the fire department is required to evacuate all occupants with mobility impairments, then, there is the possibility of locating one device per each pair (2) of expected emergency responders whose official duty would be to perform rescue functions for the building ${ }^{1}$.

Example: a fire occurs in a 20 story high-rise structure in New York City, NY. Assume that initially 10 firefighters are assigned to perform evacuation assistance. Therefore, five devices (or 10 firefighters divided by two operators each) should be distributed throughout the 20-story high-rise structure.

NOTE - if emergency stair travel devices are to be reused, there must be a chair, wheelchair, or other type of device made available for occupants with mobility impairments to transfer to once they reach the safe location area.

\subsection{The type of emergency stair travel device required}

Step 8: Of those occupants (and potential visitors) identified in Step 7, match each person's physical/medical requirements, needs, and concerns during evacuation with the capabilities of the current, available emergency stair travel devices (if possible). Since the devices differ from one manufacturer to another, even within the stair device type (i.e., within the track/belt devices), it is important to examine each device's capabilities and features and whether they match the needs of the individuals who will use them. For example, an individual may require that his/her legs are strapped into the emergency stair travel device during evacuation. Does the specific device contain these leg straps? Additionally, an individual may require physically sitting at a certain angle at all times. Does the device maintain the necessary seat angle to accommodate this need?

Step 9: Identify those emergency stair travel devices (by manufacturer and manufacturer type) that meet all physical/medical requirements, needs and concerns of the users identified in Step 7.

Step 10: Check to make sure that the devices identified in Step 9 meet the width and turning radius requirements discussed in Section 3.2 of this guidance document.

Step 11: Determine the costs associated with each device that meets Steps 8 and 9 requirements, taking into account the number of devices needed for your building. Be sure to include other

\footnotetext{
${ }^{1}$ See Section 6.4 for the explanation of the requirement for at least two operators of any stair descent device.
} 
additional costs in your budget estimate, including installation of the devices, maintenance, and safety training.

Step 12: Choose a specific device to be ordered for your building based upon requirements and cost.

\section{Emergency stair travel device location}

If a device is provided for each building occupant with mobility impairments: If a device is provided for each occupant with mobility impairments, then the device assigned to each person should be located on that individual's floor within the building. The device(s) should be located in areas of the building which can serve as temporary staging areas (or areas of refuge), i.e., areas that provides relative safety to occupants from the spread of smoke/toxic products from the fire event. An area of refuge could be a compartment of a subdivided floor, an enclosed elevator lobby, an enlarged floor-level stair landing, or a floor in a building protected throughout by a supervised automatic sprinkler system (based on the requirements in NFPA 101, Life Safety Code and the ICC International Building Code). In instances where the entire floor is considered an area of refuge, the stakeholders must decide the best location for the device. No matter where the device is located, an analysis must be performed to ensure that the device location area provides sufficient space to set up the emergency stair travel device as well as transfer the disabled individual into the device. The analysis can include a comparison of the dimensions of the determined location area with the dimensions of the maximum device use area (including device set-up and transfer). Obtaining the dimensions of the maximum device use area can be obtained through practice with the device and its users.

Stakeholders may consider locating the emergency stair travel devices inside the stairways - e.g., on the main landing of the stairways. However, during evacuation, it is likely that other evacuees will be using the landing spaces inside the stairway for travel to safety. If the stair main landing is chosen as the device location area, the building's safety official must be aware that an area [two times the stair width] long and [the stair width] wide (or smaller) may be insufficient to sustain the placement/ mounting of an emergency stair travel device - since space is required for the set-up of the device and the transfer of the individual into the device before evacuation can begin, in addition to simultaneous evacuation of other occupants inside the stairway.

If devices are provided for visitors: If devices are provided for general visitors of the building on any given day, the best location for the emergency stair travel devices is on the floors where the public are most likely to be gathered. For example, in a courthouse, emergency stair travel devices for visitors should be located on floors with courtrooms. Another acceptable location for emergency stair travel devices for visitors would be the fire command center of the building, if no specific "public" area of the building can be defined.

If devices are provided for fire department operation: If devices are provided for fire department operation during evacuation, then the fire department should determine the appropriate location for emergency stair travel devices. One option may be the fire command center. Additionally, it may be decided that the fire department will arrive to the building with the appropriate number of emergency stair travel devices. In that case, the building will not be required to locate these 
devices inside the building. It will be essential to discuss these and any other expectations with the fire department before an actual emergency occurs.

\section{Emergency stair travel device operation}

First it should be noted that the operators should follow all guidance provided by the manufacturer on the use of the specific emergency stair travel device. This guidance document is not meant to act as a replacement for any of the manufacturer's guidance documents. Instead, this document provides general guidance on evacuation procedures based exclusively on expertise derived from studying building evacuations.

Here, the term "operation” involves the following factors related to an emergency stair travel device: the transfer of the individual with mobility impairments into the emergency stair travel device, the proper location of transfer, and guidance on the device operators. Guidance on device operators includes who should assist/operate the device, the number of operators required for safe operation, the movement of the device over different components in the building (i.e., stairs versus horizontal components), and the use of these devices during the evacuation time period (i.e., when, during the evacuation, is best to introduce emergency stair travel devices in the stair flow). Each will be addressed in the following section of this guidance document.

\subsection{Transfer of the individual into the device}

It is important to speak with all disabled individuals to understand if they require assistance in the transfer or if they would prefer to transfer themselves into the emergency stair travel device. If assistance is required and requested, the following references provide guidance on appropriate lift and transfer procedures (Proulx 2002):

Schweickert-Stary, M.-T. and Hirschfeld, S. E., 1993, "Evacuate: Evacuation Techniques for Disabled and Injured Individuals", Videotape (20 min) and Training Manual, Office of Student Life, California State University, Hayward CA, 18 p.

Johnson, B., 1983, "Evacuation Techniques for Disabled Persons: Research Summary and Guidelines", National Research Council of Canada, Ottawa, 35 p.

Pauls, J. and Juillet, E., 1988, "Helping Yourself and Others in an Emergency Evacuation: A Draft Brochure", in Egress Procedures and Technologies for People with Disabilities, United States Architectural and Transportation Barriers Compliance Board, Washington, DC, 25 p.

Pauls, J. and Juillet, E., 1988, "Egress Procedures and Technologies for People with Disabilities", Prepared for the US Department of Education, Contract 300-87-0149, United States Architectural 
Additionally, the FEMA document entitled "Emergency Procedures for Employees with Disabilities in Office Occupancies” [United States Fire Administration no date; 2002] provides advice on carry or transfer procedures. The following excerpt is taken from p. 17 of the FEMA guidance document:

If you assist a wheelchair user, avoid putting pressure on the person's extremities and chest. Such pressure might cause spasms, pain and even restrict breathing. Carrying someone slung over your shoulders (something like the so called fireman's carry) is like sitting on their chest and poses danger for several individuals who fall within categories of neurologic and orthopedic disabilities." (Page 17)

Kailes [2002] also provides guidance to people with disabilities on how to "master the skill of giving quick information on how best to assist you” in an emergency. In emergencies, the individual who requires assistance is often the best person to provide critical information on how others can assist without causing injury. One example is how to safely transfer the disabled occupant into the emergency stair travel device safely and without injury. Therefore, it is important to also consult with the individual who is receiving assistance to ensure that his/her needs are being met, not only during the transfer, but during the entire evacuation.

\subsection{Location of the transfer of the individual into the device}

In general, the transfer should take place in areas of the building which provide relative safety to occupants from the spread of smoke/toxic products from the fire event. This is especially important on floors without automatic sprinkler protection.

In most cases, it will be appropriate for the disabled individual (with or without the assistant) to travel in his/her wheelchair (or with his/her mobility device) to the designated transfer area where the transfer will take place, rather than bring the device to the disabled occupant's original location. That way, the transfer can take place in a relatively safe location and the disabled individual's mobility aid can be evacuated along with the occupant, or shortly thereafter.

Similar to guidance provided in Section 4, "Emergency Stair Travel Device Location”, it is important to find a transfer location within the building that provides enough space/area to allow for the transfer to occur, without negatively influencing the evacuation of others. For this reason, stair landings may not necessarily be the best location for occupant transfer.

\subsection{Who will assist?}

The National Fire Protection Association (NFPA) (2007), Evacuation Planning for Occupants with Disabilities, provides guidance on who should provide assistance to individuals with mobility impairments during evacuation. The NFPA guidance on "who" focuses mainly on the assistance of individuals with mobility impairments who are able to travel up and down stairs easily, but have trouble operating door locks, latches and other devices. However, these suggestions are also useful in the identification of people who can help with 1) the transfer of 
individuals into an emergency stair travel device and 2) the operation of the device during stair evacuation. These "who" suggestions are included here:

- Friends or co-workers; i.e., a relative, supervisor, building staff, or floor warden

- First responders; i.e., firefighter, police officer, or a member of the emergency medical services (emergency medical technicians (EMTs) or ambulance personnel)

There are three main factors that should be considered when selecting who should provide assistance to the individual with mobility impairments:

- With whom does the person with disabilities feel most comfortable?

- With whom has the person with disabilities trained?

- When will the person with disabilities begin evacuation (i.e., with all others in the building or once the fire department arrives)?

If the disabled occupant evacuates with all others in the building, then the "who" is required to be an individual already located in the building when the emergency begins (i.e., friends or coworkers). In this case, more than one "assistant" should be assigned to each disabled occupant in case an assistant is out of the building on the day of the emergency (Proulx 2002). With sufficient training, these individuals can aid disabled occupants with the transfer and stair descent. Other guidance documents acknowledge the use of floor wardens as individuals who can assist people with disabilities during evacuation (United States Fire Administration, no date). If possible, assistants should be pre-assigned to each disabled occupant and should provide assistance in any emergency situation (i.e., they do not have to ask the individual each time if he/she needs assistance - this "buddy" arrangement has already been decided). If the assistant permanently leaves the company or building, another assistant (helper or buddy) must be assigned immediately.

If the disabled person will be assisted by emergency responders, and if they do not require immediate evacuation (i.e., with the rest of the building's population), then the building must develop a procedure by which the emergency responders (i.e., the local fire department) have a way to identify the locations of individuals who require assistance. One way to do this is supply disabled individuals with two-way communication with the fire command center or a location approved by the local fire department. Two-way communication could be in the form of a portable radio or a hard-wired device, e.g., provided in the elevator lobby on the same floor as the disabled individual.

The building must also have a plan for how to evacuate persons with mobility impairments who are visiting the building on any given day. These individuals will not have a pre-assigned "buddy" to aid them during evacuation, and will likely not be aware of the evacuation procedures. One way to ensure that there are individuals to assist disabled visitors is to have a group of building occupants who are pre-trained in the use of emergency stair travel devices during evacuation and who are not specifically assigned to any of the current building occupants. These occupants should be located on different floors or with different companies throughout the building so that they can be more accessible to visitors in need of their help. With this group in place, a disabled visitor present in the building during an emergency can receive the assistance with emergency stair travel devices during evacuation. 


\subsection{The number of operators (for track/belt type devices)}

Although one operator is often required by manufacturers to operate the track/belt type emergency stair travel devices, stakeholders should consider requiring a minimum of two individuals to operate the device, in case the primary operator is injured or incapacitated during the evacuation. When two operators are used, the primary operator should be located at the headend of the emergency stair travel device ${ }^{2}$. The secondary operator could be located at the footend of the device or could walk alongside the device during evacuation ${ }^{3}$.

However, in rare situations there are three reasons listed below as to why a minimum of four operators should be required to operate an emergency stair travel device:

- If the belt or track device contains a belt or track that is shorter in length and thus engages only one of the stair nosings at any time, at least four operators are required. The operators would consist of one at the head-end, one at the foot-end, and two back-up operators. Note: For most belt or track devices, the belt or track rests along two to three of the stair nosings at any time during stair descent, and thus, would not fall into this category.

- If the passenger is heavier than the specified weight limit for the manufacturer's oneperson operation of the device, the device must be operated by at least four operators. The operators would consist of one at the head-end, one at the foot-end, and two back-up operators.

- If the operator wishes to lift the individual and/or use the stair to transport the passenger up the stairs, at least four operators are necessary. The operators would consist of one at the head-end, one at the foot-end, and two back-up operators.

\subsection{Travel on horizontal building components}

When traveling on horizontal components, operators should tip the device so that the disabled occupant is sitting in the upright position, e.g., the person's thighs are parallel to the ground or all four wheels are touching the ground. In the upright position, devices can be pushed from the back on horizontal or flat surfaces in the building, e.g., landings, corridors on floors, and the exit corridor out of the building. For the emergency stair travel devices with wheels, especially those with 4 squarely-located wheels, the foot-end operator will not be required during travel on horizontal components.

\footnotetext{
${ }^{2}$ During stair descent, the head-end operator, i.e., the operator facing front or downward on the stairs, pushes the device on the stairs or horizontal component during evacuation.

${ }^{3}$ The foot-end operator faces the disabled occupant (i.e., the foot-end operator has his/her back to the downward direction of the stairs), guiding the chair along.
} 


\subsection{Travel during building evacuation}

This section involves the timing of the use of emergency stair travel devices during the building's evacuation. There are two options here, depending upon the needs of the disabled individual and the fire safety and evacuation plans for the building. If the disabled individual is to be evacuated via the emergency stair travel device with the rest of the population (i.e., in the same stairs), the evacuation plans should account for the fact that the device may cause congestion inside the stairways. Building management or fire safety officials can anticipate whether or not congestion will occur by understanding the following: the stair configuration (including stair width and landing size), the width of the emergency stair travel device (including any operators), and the number of operators. With an understanding of these factors, one can assess whether the operation of the emergency stair travel device within the building's stairway allows other occupants to pass.

If passing is not possible, and if one calculates the length of time that each emergency stair travel device will be located in the stairs, the length of time that congestion points (i.e., points where passing is not possible) will occur in the stairwell can be determined. If congestion within the exit stairs is anticipated, it may be more prudent to delay the use of the emergency stair travel devices until the majority of the floor population has evacuated to promote efficient flow of occupants within the exit stair during the evacuation.

In a building where there are multiple individuals who will use emergency stair travel devices, the building or fire department may wish to assign one stairway to the evacuation of emergency stair travel devices only. In this case, it would be beneficial to choose a stairway, if possible, that is most accessible to the individuals with disabilities. This stairway could be used for both evacuation of persons with mobility impairments as well as ingress of the operators (with devices) to reach additional evacuees. In this case, evacuation calculations should be performed to understand the influence of assigning one stair only to disabled evacuees on the overall building evacuation time.

\subsection{Travel after evacuation}

The final operation issue is continued travel or movement of the disabled occupant after evacuation is completed. If the building has ordered one emergency stair travel device per disabled occupant and the disabled occupant is comfortable for some extended period of time without his/her wheelchair or other movement device, then there may be little need to be concerned with the issues identified in this section of the guidance document.

In cases where the emergency stair travel devices are required to be re-used (i.e., they will be used to evacuate more than one person), the fire safety and evacuation plan must account for ways to provide mobility devices for use by the disabled individual following evacuation (National Disability Authority 2012). Extra wheelchairs can be purchased and placed on the first floor of the building for the purpose of onward transportation outside of the building. However, there may be instances where disabled individuals require their personal mobility devices immediately after evacuation is complete. Proulx (2002) states the following: 
If a person is being carried down the stairs without his or her wheelchair, it is strongly recommended that someone follow carrying the wheelchair. Non-ambulant occupants spend most of their time in wheelchairs. They will feel much more comfortable and secure once they have reached safety if they can get back into their wheelchair as soon as possible. Without their chairs, they lose their autonomy and are completely dependent on others to move around. (p.13)

One option to relocate the personal mobility devices, i.e., wheelchairs, is requiring an operator (or two) to carry the wheelchair down the steps behind, alongside, or in front of the emergency stair travel device. If congestion within the exit stairs during the wheelchair carry is anticipated, it may be more prudent to delay the use of the emergency stair travel devices until the majority of the floor population has evacuated to promote efficient flow of occupants within the exit stair during the evacuation.

\section{Emergency stair travel device training}

Prior to the use of emergency stair travel devices in an actual building fire emergency, training must occur. There are two types of training that should accompany the use of these devices: initial training and refresher training. Initial training is the first set of training courses that any one person would receive in order to operate or use an emergency stair travel device. Then, once an individual receives initial training, refresher training occurs on a regular basis to ensure that knowledge and skills are current. Both disabled occupants and any individual who is assigned or might be assigned to assist individuals using emergency stair travel devices during evacuation must attend both initial and refresher training courses.

Initial training should consist of both classroom-based and practical elements. The classroombased portion of the training could cover all aspects of the device's user's guide and Sections 4 and 5 of this guidance document. Additionally, disabled occupants and any assistance individuals who attend the classroom-based initial training should be provided with personal copies of the device's user's guide.

Initial training should also consist of actual practice with the emergency stair travel device(s) purchased by the building. Operators of the device should practice setting up the device per the instructions included in the user's guide, transferring an individual into the device (if they will be engaged in that behavior), operating the device on horizontal building components, preparing for stair travel per the instructions included in the user's guide, and operating the device on stairways (at least three floors so that practice on landings can occur). Operators should practice with the disabled person whom they will assist, if willing. Disabled users should also practice personal transfer, preparation for stair travel, and actual stair descent (preferably with the operator assigned to assist them, if applicable).

Once initial training is received, operators and disabled users should be required to attend the practical portion of the original (initial) training course (as outlined above) two times per year. This is defined as refresher training. 


\section{Emergency stair travel device maintenance}

Regular maintenance is crucial to ensure that the emergency stair travel devices will operate appropriately and effectively when/if a building fire emergency occurs. Please refer to the RESNA ED-1 Evacuation Devices Volume 1: Emergency Stair Travel Devices for Individuals with Disabilities (RESNA 2013) for maintenance and inspection requirements. Also, the user's guide for each emergency stair travel device should be consulted for helpful information on maintenance.

\section{Conclusions}

The guidance provided in this document is meant to aid stakeholders involved in the evacuation decision making process to determine whether the use of emergency stair travel devices for evacuation of persons unable to negotiate exit stairs would be appropriate and feasible in their building. The document begins by providing guidance on the types of emergency stair travel devices currently available on the market, and then focuses specifically on devices which use a track or belt system for evacuation. Therefore, the rest of the document provides guidance on the decisions that need to be made involving the use of these specific types of belt/track devices. Guidance is also provided on the factors that need to be taken into account prior to deciding on whether the use of emergency stair travel devices for evacuation in the building is appropriate. Once the decision has been made that the use of these devices is appropriate for your building, guidance is provided on selecting the number of type of device for your building, as well as where to locate the devices, how to operate them during evacuation, appropriate training techniques, and maintenance of the devices. 


\section{References}

Hedman, Glenn. 2009. "Stair Descent Devices: An overview of current devices and proposed framework for standards and testing.” Pp. 601-606 in The $4^{\text {th }}$ International Symposium on Human Behaviour in Fire. London, UK: Interscience communications.

Hedman, Glenn. 2010. "Travel Along Stairs by Individuals with Disabilities: A summary of devices used during routine travel and travel during emergencies.” Pp. 109-119 in Pedestrian and Evacuation Dynamics, R.D. Peacock, E.D. Kuligowski and J.D. Averill (eds), NY: Springer.

International Building Code. 2012. “2012 International Building Code”, International Code Council, Washington DC.

Kailes, June Isaacson. Evacuation Preparedness: Taking Responsibility For Your Safety: A Guide For People With Disabilities and Other Activity Limitations, 2002. Published and distributed by Center for Disability Issues and the Health Professions, Western University of Health Sciences, 309 E. Second Street, Pomona, CA 91766-1854, Voice: (909) 469-5380, TTY: (909) 469-5520, Fax: (909) 469-5407, Email:evac@westernu.edu.

National Disability Authority. "Promoting Safe Egress and Evacuation for People with Disabilities” (website), Accessed 2012. http://www.nda.ie/cntmgmtnew.nsf/0/195244135ECA466B8025741F00529C24/\$File/Egress6.ht $\underline{\mathrm{ml}}$.

National Fire Protection Association. 2012. NFPA 101, Life Safety Code, 2012 Edition, National Fire Protection Association, Quincy, MA.

National Fire Protection Association. 2007. "Emergency Evacuation Planning Guide for People with Disabilities.” Quincy, MA: National Fire Protection Association.

Proulx, G. 2002. “Evacuation Planning for Occupants with Disability.” Internal Report No. 843. Ottawa: National Research Council Canada.

RESNA. 2013. "RESNA ED-1 Evacuation Devices Volume 1: Emergency Stair Travel Devices for Individuals with Disabilities"

Social Security Administration, “Social Security Basic Facts.” Accessed December 13, 2012. http://www.ssa.gov/pressoffice/basicfact.htm

United States Fire Administration (under FEMA). 2002. “Orientation Manual for Fire Responders on the Evacuation of People with Disabilities.” Emmitsburg, MD: USFA.

United States Fire Administration (under FEMA). No date. "Emergency Procedures for Employees with Disabilities in Office Occupancies.” Emmitsburg, MD: USFA. 
United States Fire Administration. 1999. “Fire Risks for the Mobility Impaired.” Emmitsburg, MD: USFA.

U.S. Census Bureau, 2011. “American Community Survey 1-Year Estimates.” Accessed December 13, 2012. 